\title{
Damage Assessment of the Equine Sperm Membranes by Fluorimetric Technique
}

\author{
Eneiva Carla Carvalho Celeghini, André Furugen Cesar de Andrade, Cláudia Fernandes \\ Raphael, Juliana Nascimento, Janahi Souza Ticianelli and Rubens Paes de Arruda* \\ Laboratório de Biotecnologia do Sêmen e Andrologia; Departamento de Reprodução Animal; Faculdade de \\ Medicina Veterinária e Zootecnia; Universidade de São Paulo - USP; Av. Duque de Caxias Norte, 225; 13635-900; \\ C. P.: 23; Campus da USP; Pirassununga - SP - Brasil
}

\begin{abstract}
To validate a practical technique of simultaneous evaluation of the plasma, acrosomal and mitochondrial membranes in equine spermatozoa three fluorescent probes (PI, FITC-PSA and MITO) were associated. Four ejaculates from three stallions $(n=12)$ were diluted in TALP medium and split into 2 aliquots, 1 aliquot was flash frozen in liquid nitrogen to induce damage in cellular membranes. Three treatments were prepared with the following fixed ratios of fresh semen: flash frozen semen: 100:0 (T100), 50:50 (T50), and 0:100 (T0). A 150- $\mu \mathrm{L}$ aliquot of diluted semen of each treatment was added of $2 \mu \mathrm{L}$ of PI, $2 \mu \mathrm{L}$ of MITO and $80 \mu \mathrm{L}$ of FITC-PSA; incubated at $38.5^{\circ} \mathrm{C} / 8 \mathrm{~min}$, and sperm cells were evaluated by epifluorescent microscopy. Based in regression analysis, this could be an efficient and practical technique to assess damage in equine spermatozoa, as it was able to determine the sperm percentage more representative of the potential to fertilize the oocyte.
\end{abstract}

Key words: Stallion, acrosome, plasma membrane, mitochondria, fluorescent probes

\section{INTRODUCTION}

The male infertility can be diagnosed by semen evaluation; however, some damages can not be found by usual techniques, and needs specific procedures to detect the injury, especially in sperm membranes. Studies have been carried out to develop new techniques for seminal evaluation. Among these, great emphasis has been given to fluorescent probes by epifluorescence microscopy or flow cytometry system (Graham et al., 1990, Celeghini et al. 2007; Andrade et al., 2007; Celeghini et al., 2008). Fluorescence is a sensible and specific indicator of the state of some molecules, so that it can be applied as a method to measure the metabolic changes in the living cells (Haugland, 2001; Santos et al., 2008).

The integrity of sperm membrane is crucial for the maintenance of the sperm fertilizing capability. The plasma membrane is responsible for the preservation of cellular homeostasis; in this way the plasma membrane integrity exerts a vital role on sperm survival in the female reproductive tract and on the preservation of its fertility capability (Õura and Toshimori, 1990). Acrosome integrity is essential for the occurrence of oocyte fertilization since the acrosome reaction is fundamental for sperm penetration into the zona pellucida and for oocyte plasma membrane fusion (Õura and Toshimori, 1990; Flesch and Gadella, 2000). The mitochondrial membrane potential, responsible for

\footnotetext{
*Author for correspondence: arrudarp@usp.br
} 
ATP production, is indispensable for the flagellar beat and sperm motility (Flesch and Gadella, 2000).

Some fluorescent probes, specific for each cellular compartment have been employed. Propidium iodide (PI), a specific stain that binds to DNA, does not cross the intact plasma membrane, and it emits a red fluorescence when bound to the nucleus of a damaged plasma membrane cell (Garner et al., 1986; Garner et al., 1988; Graham et al., 1990; Arruda et al., 2003). Pisum sativum agglutinin (PSA), when conjugated to lectin fluorescent (FITC) marks the damaged acrosome with a yellow-green color (Cross et al., 1986; Graham et al., 1990; Casey et al., 1993; Hasenack et al., 2002; Arruda et al., 2003). PSA is an agglutinin from edible pea that binds to glycoconjugates of acrosomal matrix (Cross and Meizel, 1989); it has affinity for terminal $\alpha-D-$ glucosyl and $\alpha$-D-mannosyl residues of glycoproteins, and it binds specifically to the sugar $\alpha$-mannoside found in the acrosomal contents (Cross et al., 1986). MitoTracker Green FM (MITO) is a fluorescent probe that has specificity for active mitochondrial membranes, staining in bright green sperm midpieces that have membrane potential mitochondrias (Garner et al., 1997).

Fluorescent probes association has been shown to permit simultaneous evaluation of several sperm cell compartments, such as plasma membrane and acrosome integrity (Centola et al., 1990; Graham et al., 1990; Casey et al., 1993; Way et al., 1995; Sukardi et al., 1997; Thomas et al., 1997; Arruda et al., 2002; Arruda et al., 2003; Nagy et al., 2003). Graham et al. (1990) demonstrated that at least three bovine sperm compartments can be simultaneously evaluated by the addition of three probes. They utilized PI for the evaluation of plasma membrane integrity, PSA to determine the acrosomal integrity, and Rhodamine 123 to verify the mitochondrial function. For equine sperm Papaioannou et al. (1997) assessed plasma membrane integrity and mitochondrial function using a double-staining, PI and R123, respectively; Love et al. (2003) evaluated plasma membrane integrity using SYBR-14 and PI associated to JC-1 to mitochondrial function.

The more spermatological parameters are evaluated in a semen sample, the higher the value on the in vitro fertility prognostic will be (Tartaglione and Ritta, 2004). Thus, this experiment was designed to validate a technique of simultaneous evaluation of plasma, acrosomal and mitochondrial membranes in equine spermatozoa, using the association of the following fluorescent probes: PI, FITC-PSA and MITO, respectively.

\section{MATERIALS AND METHODS}

\section{Semen Preparation}

Four ejaculates from each of three different stallions $(\mathrm{n}=12)$, all showing motility $\geq 80 \%$ and abnormal morphology $\leq 10 \%$, were diluted in TALP medium (Bavister et al., 1983) to a final concentration of $25 \times 10^{6}$ spermatozoa $/ \mathrm{mL}$. The diluted semen was split into two aliquots; one aliquot was flash frozen in liquid nitrogen and thawed in three continuous cycles to induce the damage in cellular membranes and to perturb the mitochondrial function. Three treatments were prepared with the following fixed ratios of fresh semen: flash frozen semen: 100:0 (T100), 50:50 (T50), and 0:100 (T0).

\section{Spermatozoa Staining}

The three samples (T100, T50 and T0) were submitted to a stain technique modified from Celeghini et al. (2007). A $150-\mu \mathrm{L}$ aliquot from each diluted semen sample was placed into a microcentrifuge tube, with the addition of $2 \mu \mathrm{L}$ of PI (3 mM, Sigma, 28,707-5), $2 \mu \mathrm{L}$ of MITO (1 $\mathrm{mM}$, Molecular Probes, M-7514) and $80 \mu \mathrm{L}$ of FITC-PSA (100 $\mu \mathrm{g} / \mathrm{mL}$, Sigma, L-0770). Samples were incubated at $38.5^{\circ} \mathrm{C}$ for 8 minutes in the dark.

\section{Fluorescent Examination}

An $8-\mu \mathrm{L}$ of semen sample was put on a slide, coverslipped and evaluated immediately by the epifluorescent microscopy (Nikon, model Eclipse 80i) in a triple filter (D/F/R, C58420), showing a set: UV-2E/C (excitation 340-380 nm and emission 435-485 nm), B-2E/C (excitation 465$495 \mathrm{~nm}$ and emission 515-555 $\mathrm{nm}$ ), and G-2E/C (excitation 540-525 $\mathrm{nm}$ and emission 605-655 $\mathrm{nm})$, at 1,000x magnification. Two hundred sperm cells per slide were examined and classified based on the fluorescence emitted by each probe.

\section{Statistical Analysis}

The mean and standard deviation from the treatments T100, T50 and T0 were obtained and their effects were evaluated by the analysis of variance (ANOVA). The means across all samples 
were compared by Fisher's LSD test. Upon finding the significant differences $(\mathrm{P}<0.01)$ between the treatments, the data obtained for plasma membrane integrity, intact acrosome, and mitochondrial function (dependent variables) for each treatment (independent variable) were submitted to linear regression using StatView software (SAS Institute, 2.ed., Cary, NC, USA, 1998).

\section{RESULTS}

The fluorescent probes association results were ranked in eight cell classes (Table 1), according to plasma membrane integrity, intact acrosome and mitochondrial function (Fig. 1).

Table 1 - Classification of equine sperm cells according to fluorescence emitted by PI, FITC-PSA e MITO probes.

\begin{tabular}{|c|c|c|c|}
\hline Sperm Cell Category & $\mathbf{P I}^{1}$ & FITC-PSA ${ }^{2}$ & MITO $^{3}$ \\
\hline Intact plasma membrane, intact acrosome and mitochondrial function (IPIAF) & - & - & + \\
\hline Intact plasma membrane, intact acrosome and without mitochondrial function (IPIAW) & - & - & - \\
\hline Intact plasma membrane, damage acrosome and mitochondrial function (IPDAF) & - & + & + \\
\hline Intact plasma membrane, damage acrosome and without mitochondrial function (IPDAW) & - & + & - \\
\hline Damage plasma membrane, intact acrosome and mitochondrial function (DPIAF) & + & - & + \\
\hline Damage plasma membrane, intact acrosome and without mitochondrial function (DPIAW) & + & - & - \\
\hline Damage plasma membrane, damage acrosome and mitochondrial function (DPDAF) & + & + & + \\
\hline $\begin{array}{l}\text { Damage plasma membrane, damage acrosome and without mitochondrial function } \\
\text { (DPDAW) }\end{array}$ & + & + & - \\
\hline
\end{tabular}

${ }^{1}$ PI positive $(+)=$ red stained nucleus. ${ }^{2}$ FITC-PSA positive $(+)=$ yellow-green acrosome region. ${ }^{3}$ MITO positive $(+)=$ bright green in midpiece region.

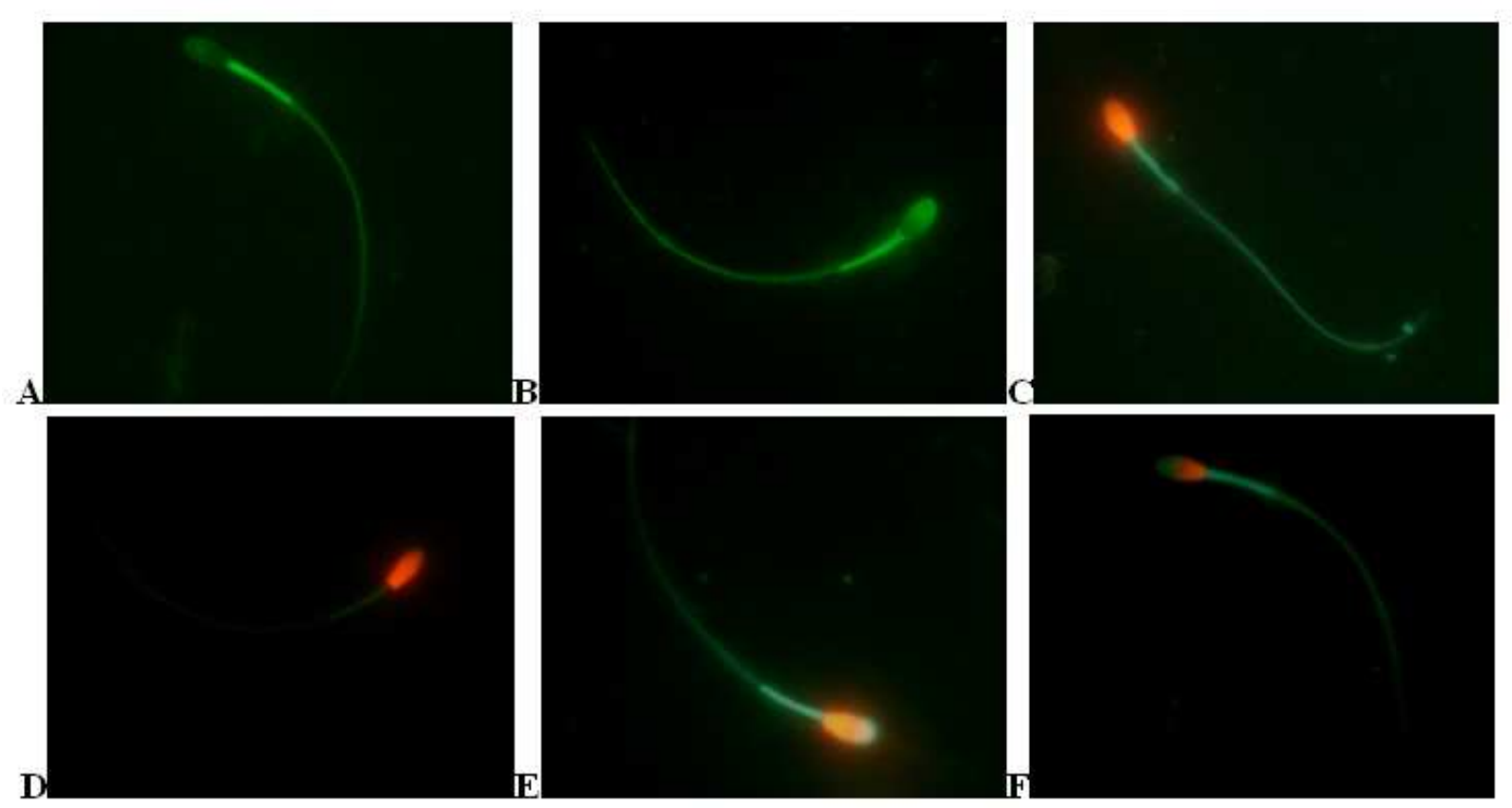

Figure 1 - Photomicrography of equine spermatozoa stained with PI, FITC-PSA and MITO. A) Intact plasma membrane, intact acrosome, and mitochondrial function, B) Intact plasma membrane, damaged acrosome, and mitochondrial function, C) Damaged plasma membrane, intact acrosome, and mitochondrial function, D) Damaged plasma membrane, intact acrosome, and without mitochondrial function, E) Damaged plasma membrane, damaged acrosome, and mitochondrial function, F) Damaged plasma membrane, damaged acrosome, and without mitochondrial function. 
Significant effects were observed (ANOVA; $\mathrm{P}<0.01)$ among the treatments $\mathrm{T} 100$, T50 and T0 on the mean percentage of spermatozoa displaying plasma membrane integrity, intact acrosome, and mitochondrial function, separately and the category of cells showing simultaneously plasma membrane integrity, acrosomal integrity and mitochondrial function (IPIAF). The treatments differed significantly (Fisher test, $\mathrm{P}<0.01$ ) in all the variables (Table 2).
The regression analysis results for the plasma membrane integrity, detected by PI, are displayed in Fig. 2A. Acrosome integrity, detected by the FITC-PSA probe is shown in Fig. 2B; and mitochondrial function, estimated by MITO is displayed in Fig. 2C. Fig. 3 shows the regression equation of IPIAF.

Table 2 - Mean \pm standard deviation of equine sperm intact plasma membrane (IPM), intact acrosome (IA) and mitochondrial function (MF) in T100, T50 and T0 treatments.

\begin{tabular}{lccc}
\hline Characteristic & T100 & T50 & T0 \\
\hline IMP & $79.3 \pm 8.8^{\mathrm{a}}$ & $43.1 \pm 10.3^{\mathrm{b}}$ & $2.1 \pm 2.0^{\mathrm{c}}$ \\
IA & $84.5 \pm 7.8^{\mathrm{a}}$ & $47.9 \pm 8.5^{\mathrm{b}}$ & $6.0 \pm 3.3^{\mathrm{c}}$ \\
MF & $86.0 \pm 7.3^{\mathrm{a}}$ & $51.5 \pm 10.8^{\mathrm{b}}$ & $8.0 \pm 5.3^{\mathrm{c}}$ \\
IPIAF & $78.0 \pm 8.1^{\mathrm{a}}$ & $40.8 \pm 9.3^{\mathrm{b}}$ & $1.5 \pm 1.6^{\mathrm{c}}$ \\
\hline
\end{tabular}

Different superscript letters in the same line indicate statistical differences $(\mathrm{P}<0.01)$.
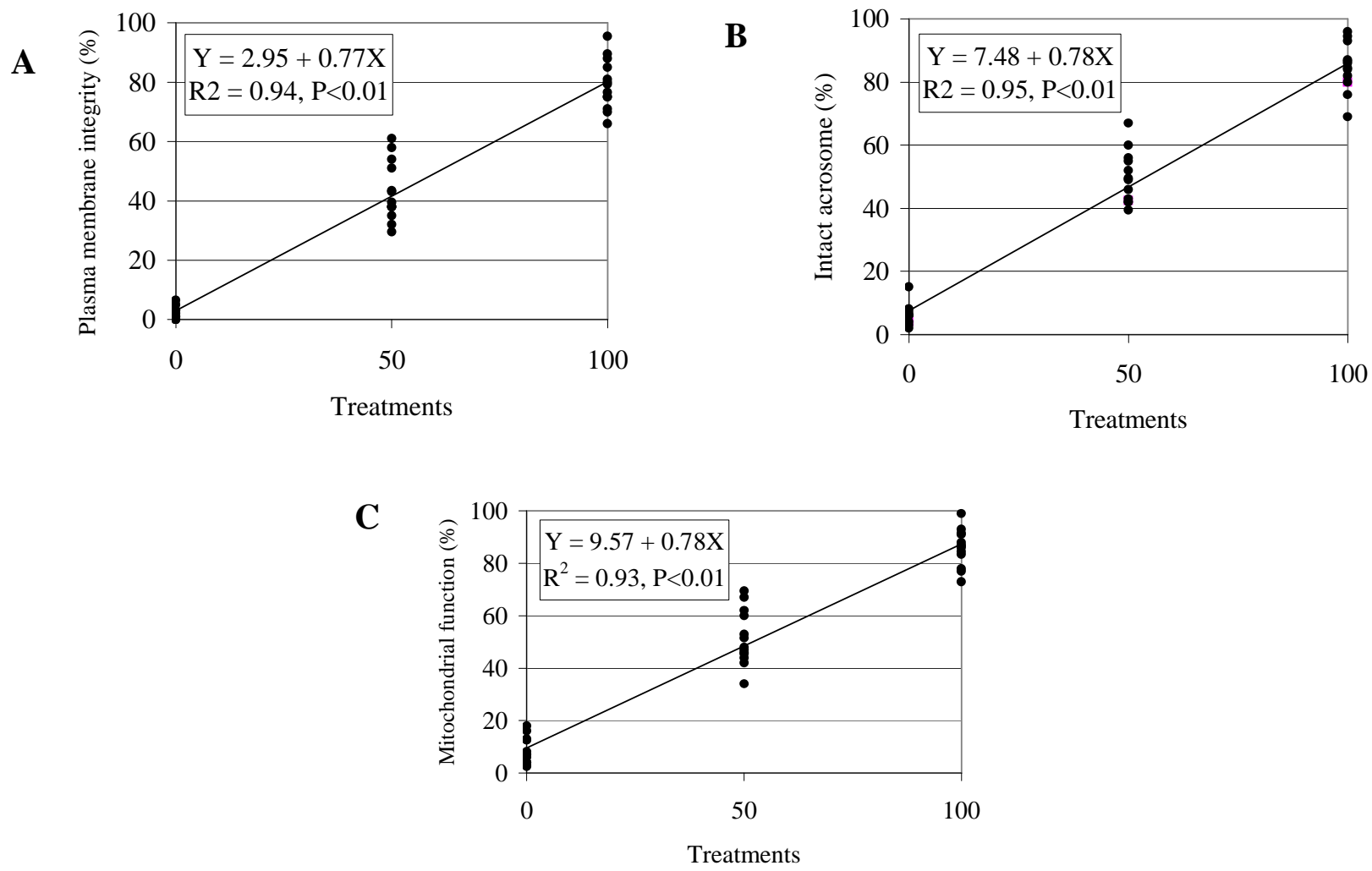

Figure 2 - Regression analysis of plasma membrane integrity, detected by PI (A), intact acrosome, verify by FITC-PSA (B), and mitochondrial function, marked by MITO (C) of equine spermatozoa submitted to treatments T0 (Fresh semen:Flash frozen semen, 0:100), T50 (Fresh semen:Flash frozen semen, 50:50) and T100 (Fresh semen:Flash frozen semen, 100:0). 


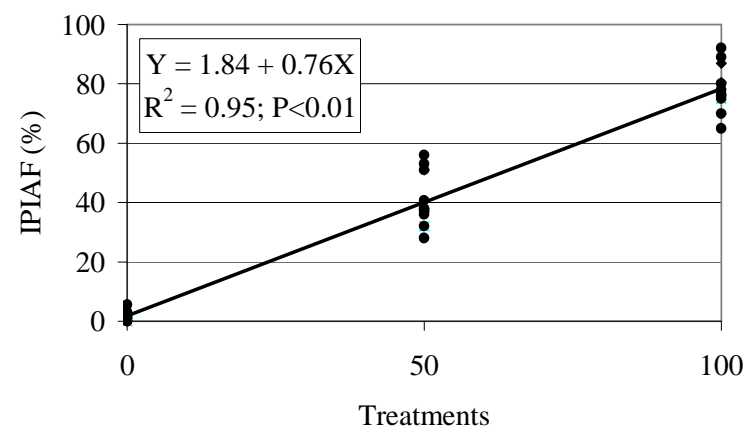

Figure 3 - Regression analysis of equine sperm showing intact plasma, intact acrosome and mitochondrial function (IPIAF), verified by PI/FITC-PSA/MITO association, in spermatozoa submitted to treatments T0 (Fresh semen:Flash frozen semen, 0:100), T50 (Fresh semen:Flash frozen semen, 50:50) and T100 (Fresh semen:Flash frozen semen, 100:0).

\section{DISCUSSION}

The possibility of association of fluorescent probes for the evaluation of spermatozoa has been described in the literature (Graham et al., 1990; Centola et al., 1990; Henley et al., 1994; Sukardi et al., 1997; Papaioannou et al., 1997; Arruda et al., 2002; Huo et al., 2002; Arruda et al., 2003; Nagy et al., 2003; Love et al., 2003; Andrade et al., 2007; Celeghini et al., 2008). However, most of the techniques allow evaluating simultaneous only plasma and acrosomal membranes. The association of PI and FITC-PSA probes for the evaluation of plasma and acrosomal membranes integrity, respectively, as utilized in this experiment, has been reported for ovine (Sukardi et al., 1997), human (Centola et al., 1990), bovine (Graham et al., 1990), and equine (Arruda et al., 2002; Arruda et al., 2003) sperm. PI was also associated with the probes for mitochondrial function evaluation; high positive correlations $(r>0.96)$ were found between R123, MITO and JC1 , and sperm motility in bovine (Garner et al., 1997). This experiment validated the association of three fluorescent probes PI, FITC-PSA and MITO to evaluation of plasma and acrosomal membranes, as well as mitochondrial function in stallion sperm.

Some tests were performed to obtain a highrepeatability technique producing an accurate description of the status of each cellular membrane. These tests are necessary to identify which probes work better together since some probes when associated to others can present divergent results, changing its characteristics and fluorescence standard.

PI, FITC-PSA and MITO resulted in very consistent marking of spermatozoa, making it easy to identify the structure to be evaluated. The PI and MITO probes association was mentioned by Garner et al. (1997) in bovine spermatozoa, but no validation treatment was cited by these authors. The T100, T50 and T0 treatment were prepared to validate this technique, following a methodology described by Thomas et al. (1997). Results of ANOVA and Fisher test revealed that all the treatments were efficient, and consequently the technique validation could be submitted to linear regression analysis. The MITO dye is substantially more photostable than widely used Rhodamine 123 fluorescent dye and produces a brighter, more mitochondrion-selective signal at lower concentrations (Papaioannou et al., 1997). Because its emission maximum is blue-shifted approximately $10 \mathrm{~nm}$ relative to the emission maximum of Rhodamine 123, the MITO dye produces a fluorescent staining pattern that should be better resolved from that of red-fluorescent probes in double-labeling experiments.

The validation of this technique was performed to verify if it could be applied with assurance on the evaluation of equine sperm. On the equation obtained by regression analysis for plasma membrane integrity evaluated by exclusion of PI from nucleus (Fig. 2A), it was possible to verify that the value of intercept next to zero (2.95), as would be expected from a sample that was submitted to flash freezing, with the objective of 
damaging all the membranes. The value of the regression coefficient was also next of the expected (0.77), as T100 represented a sample with at least $80 \%$ of motility. The coefficient of determination of $94 \%$ confirmed these observations. Similar results were observed by Graham et al. (1990), who compared PI efficiency separately using a stain technique by eosin/nigrosin, finding a positive correlation $(\mathrm{r}=0.78)$ between the techniques, with a confidence interval of $95 \%$. A positive correlation between PI and eosin/nigrosin has also been observed in $\operatorname{dog}(\mathrm{r}=0.88)$ (Peña et al., 1999), boar $(\mathrm{r}=0.71)$ and bull $(\mathrm{r}=0.83)$ (Pintado et al., 2000) sperm. Pintado et al. (2000) observed high positive correlations between PI and $\mathrm{H} 258$ in swine $(\mathrm{r}=0.96)$ and bovine $(\mathrm{r}=0.94)$ sperm as well.

Similar coefficients had been observed for the same association, on a regression equation calculated for acrosome integrity (Fig. 2B), verified by FITC-PSA probe, in which the value of the intercept was 7.48 , the regression coefficient was 0.78 , and the determination coefficient was $95 \%$. The FITC-PSA efficiency was evaluated by Graham et al. (1990) comparing it to naphthol yellow/erythrosin $b$.

The equation obtained for mitochondrial function, with MITO associated to PI and FITC-PSA, showed similar results to that of plasma membrane integrity and acrosomal integrity $(\mathrm{Y}=9.57+$ 0.78X, $\left.\quad \mathrm{R}^{2}=0.93\right)$. Over all, one observed characteristic about MITO was that it emited bright green fluorescence when bound to mitochondria with membrane potential. However, it was important to observe that MITO also bound to the parts of sperm membrane on its head and tail in an unspecific form, emitting a less intense fluorescence as was also observed by Garner et al. (1997). This unspecific binding of MITO is certainly beneficial for the evaluation, as it then becomes possible to visualize a cell sketch with intact plasma membrane, even though it is necessary to recognize stain nuances among those midpieces with and without mitochondrial function. In an attempt to seek more objectivity in these associations with bovine sperm, Celeghini et al. (2007) validated three techniques of fluorescent probes for the simultaneous evaluation of plasma, acrosomal and mitochondrial membranes, between them, two techniques were used with: PI, Hoechst 33342, FITC-PSA, or CMXRos or JC-1, obtaining very consistent results. It is important to remember, however, that the addition of one more probe (Hoechst 33342) increases the technique's cost.

Celeghini et al. (2007) obtained a regression equation, for the same association of probes (PI, FITC-PSA and MITO) in bovine sperm $(Y=35.0+0.55 X)$, which was different from the expected in spite of its high determination coefficient $\left(\mathrm{R}^{2}=0.84\right)$. The elucidation to these differences could be in differences among the species or in more technical ability to differentiate the stain nuances of MITO when bound to mitochondrial membranes with or without potential.

Recently, Celeghini et al. (2008) and Nascimento et al. (2008) utilized the fluorescent probes association to evaluate the effects of the cryopreservation on bovine and equine sperm membranes, respectively. Graham et al. (1990) associated the fluorescent probes to evaluate the bovine sperm, but they utilized a flow cytometry technique. Although this technique promotes better analyses, the high cost of flow cytometry makes it not available in most of the analysis semen laboratory in the world. The epifluorescence microscopy is more accessible and brings excellent results for sperm evaluation.

Based on the equations and on the high coefficients of determination it could be concluded that this was an efficient and practical technique to simultaneous evaluate the plasma, acrosomal and mitochondrial membranes in equine spermatozoa, which in turn could determine the sperm percentage more representative of the potential to fertilize the oocyte.

\section{ACKNOWLEDGMENTS}

The authors would like to thank to FAPESP for financial support, processes n. 00/14653-6 and 01/13940-4.

\section{RESUMO}

Para validar uma técnica prática de avaliação simultânea das membranas plasmática, acrossomal e mitocondrial em espermatozóides eqüinos três sondas fluorescentes (PI, FITC-PSA e MITO) foram associadas. Quatro ejaculados de três garanhões $(n=12)$ foram diluídos em meio TALP e divididos em duas alíquotas, uma alíquota foi 
submetida a flash frozen em nitrogênio líquido para induzir danos nas membranas celulares. Três tratamentos foram preparados com as seguintes proporções de sêmen fresco: sêmen flash frozen: 100:0 (T100), 50:50 (T50), e 0:100 (T0). Uma amostra de $150 \mu \mathrm{L}$ de sêmen diluído de cada tratamento foi adicionada de $2 \mu \mathrm{L}$ de PI, $2 \mu \mathrm{L}$ de MITO e $80 \mu \mathrm{L}$ de FITC-PSA; incubadas à $38,5^{\circ} \mathrm{C} / 8 \mathrm{~min}$, e as células espermáticas foram avaliadas por microscopia de epifluorescência. Baseados na análise de regressão esta é uma técnica eficiente e prática para determinar danos em espermatozóides eqüinos, capaz de determinar a porcentagem de espermatozóides mais representativa do potencial fertilizante do ovócito.

\section{REFERENCES}

Andrade, A.F.C.; Arruda, R.P.; Celeghini, E.C.C.; Nascimento, J.; Martins, S.M.M.K.; Raphael, C.F. and Moretti, A.S. (2007), Fluorescent stain method for the simultaneous determination of mitochondrial potencial and integrity of plasma and acrosomal membranes in boar sperm. Reprod Dom Anim., 42, 190-194.

Arruda, R.P.; Ball, B.A.; Gravance, C.G. and Liu, I.K.M. (2003), Flow cytometric membrane and acrosomal integrity of the stallion spermatozoa. Acta Scientiae Vet., 31, 226-227. (abstract).

Arruda, R.P.; Souza, N.L.; Marques, A.; Celeghini, E.C.C.; Gobesso, A.A.O.; Meirelles, F.V.; Binelli, M. and Blasques, F.J.H. (2002), Evaluation of techiniques using CFDA/PI, H258/FITC-PSA and Trypan Blue/Giemsa for assessment of the viability and acrosomal integrity of cryopreserved equine spermatozoa. Theriogenology, 57, 477. (abstract).

Bavister, B.D.; Leibfried, M.L. and Lieberman, G. (1983), Development of preimplantation embryos of the golden hamster in a defined culture medium. Biol Reprod., 28, 235-47.

Casey, P.J.; Hillman, R.B.; Robertson, K.R.; Yudin, A.I.; Liu, I.K.M. and Drobins, E.Z. (1993), Validation of an acrosomal stain for equine sperm that differentiates between living and dead sperm. $J$ Androl., 14, 289-297.

Celeghini, E.C.C., Arruda, R.P.; Andrade, A.F.C.; Nascimento, J. and Raphael, C.F. (2007), Practical techniques for bovine sperm simultaneous fluorimetric assessment of plasma, acrosomal and mitochondrial membranes. Reprod Dom Anim., 42, 479-488.

Celeghini, E.C.C.; Arruda, R.P.; Andrade, A.F.C.; Nascimento, J.; Raphael, C.F. and Rodrigues, P.H.M. (2008), Effects that bovine sperm cryopreservation using two different extenders has on sperm membranes and chromatin. Anim Reprod Sci., 104, 119-131.

Centola, G.M.; Mattox, J.H.; Burde, S. and Leary, J.F. (1990), Assessment of the viability and acrosome status of fresh and frozen-thawed human spermatozoa using single-wavelength fluorescence microscopy. Mol Reprod Develop., 27, 130-135.

Cross, N.L. and Meizel, S. (1989), Methods for evaluating the acrossomal status of mammalian sperm. Biol Reprod, 41, 635-641.

Cross, N.L.; Morales, P.; Overstreet, J.W. and Hanson, F.W. (1986), Two simple methods for detecting acrosome - reacted human sperm. Gam Res., 15, 213226.

Flesch, F.M. and Gadella, B.M. (2000), Dynamics of the mammalian sperm membrane in the process of fertilization. Biochim Bioph Acta, 1469, 197-235.

Garner, D.L.; Johnson, L.A. and Allen, C.H. (1988), Fluorimetric evaluation of criopreserved bovine spermatozoa extended in egg yolk and milk. Theriogenology, 30, 369-378.

Garner, D.L.; Pinkel, D.P.; Johnson, L.A. and Pace, M.M. (1986), Assessment of spermatozoal function using dual fluorescent staining and flow cytometric analysis. Biol Reprod., 34, 127-138.

Garner, D.L.; Thomas, A.C.; Joerg, H.W.; Dejarnette, J.M. and Marshall, C.E. (1997), Fluorometric assessments of mitochondrial function and viability in cryopreserved bovine spermatozoa. Biol Reprod., 57, 1401-06.

Graham, J.K.; Kunze, E. and Hammerstedt, R.H. (1990), Analysis of sperm cell viability, acrosomal integrity, and mitochondrial function using flow cytomitry. Biol Reprod., 43, 55-64.

Hasenack, B.S.; Botelho, M.V.J.; Lauretti, F.; Melo, F.L.; Orlandi, J.M.; Linhares, R.E.C.; Ueda, M. and Nozawa, C.M. (2002), The effect of concanavalin A on the replication of rotavirus (SA-11) in cell culture. Braz Arch Biol Technol., 45, 125-135.

Haugland, R.P. (2001), Handbook of fluorescent probes and research chemicals. Molecular Probes, Oregon.

Henley, N.; Baron, C. and Roberts, K.D. (1994), Flow cytometric evaluation of the acrosome reaction of human spermatozoa: a new method using a photoactivated supravital stain. Int J Androl., 17, 7884.

Huo, L.J.; Ma, X.H. and Yang, Z.M. (2002), Assessment of sperm viability, mitochondrial activity, capacitation and acrosome intactness in extended boar semen during long-term storage. Theriogenology, 58, 1349-1360.

Love, C.C.; Thompson, J.A.; Brinsko, S.P.; Rigby, S.L.; Blanchard, T.L.; Lowry, V.K. and Varner, D.D. (2003), Relationship between stallion sperm motility and viability as detected by two fluorescence staining techniques using flow cytometry. Theriogenology, 60 , $1127-1138$ 
Nagy, S.; Jansen, J.; Topper, E.K. and Gadella, B.M. (2003), A triple-stain flow cytometric method to assess plasma -and acrosome membrane integrity of cryopreserved bovine sperm immediately after thawing in presence of egg-yolk particles. Biol Reprod., 68, 1828-1835.

Nascimento, J.; Andrade, A.F.C.; Raphael, C.F.; Celeghini, E.C.C. and Arruda, R.P. (2008), Effects of sperm concentration and volume of straws on motion characteristics and plasma, acrosomal and mitochondrial membranes of equine cryopreserved spermatozoa. J Equine Vet Sci., 28, 351-358.

Õura, C. and Toshimori, K. (1990), Ultrastructural studies on the fertilization of mammalian gametes. Int Rev Cytol., 122, 105-151.

Papaioannou, K.Z.; Murphy, R.P.; Monks, R.S.; Hynes, N.; Ryan, M.P.; Boland, M.P. and Roche, J.F. (1997), Assessment of viability and mitochondrial function of equine spermatozoa using double staining and flow cytometry. Theriogenology, 48, 299-312.

Peña, A.L.; Quintela, L.A. and Herradón, P.G. (1999), Flow cytometric assessment of acrosomal status and viability of dog spermatozoa. Reprod Dom Anim, 34, 495-502.

Pintado, B.; De La Fuente, J. and Roldan, E.R.S. (2000), Permeability of boar and bull spermatozoa to the nucleic acid stains propidium iodide or Hoechst 33258 , or the eosin: accuracy in the assessment of cell viability. J Reprod Fertil, 118, 145-152.
Santos, N.G.; Amaral, A.; Cavalcanti, M.B.; Neves, M.A.B. and Machado, C.G.F. (2008), Flow cytometry protocol to evaluate ionizing radiation effects on $\mathrm{P}$ glycoprotein activity. Braz Arch Biol Technol., 51, 109-120.

Stat View. Using Statview, SAS Institute Inc. second edition, 1998. 288p.

Sukardi, S.; Curry, M.R. and Watson, P.F. (1997), Simultaneous detection of the acrosomal status and viability of incubated ram spermatozoa using fluorescent markers. Anim Reprod Sci., 46, 89-96.

Tartaglione, C.M. and Ritta, M.N. (2004), Prognostic value of spermatological parameters as predictors of in vitro fertility of frozen-thawed bull semen. Theriogenology, 62, 1245-1252.

Thomas, C.A.; Garner, D.L.; Dejarnette, J.M. and Marshall, C.E. (1997), Fluorometric assessments of acrossomal integrity and viability in cryopreserved bovine spermatozoa. Biol Reprod., 56, 991-998.

Way, A.L.; Henault, M.A. and Killian, G.J. (1995), Comparison of four staining methods for evaluation acrosome status and viability of ejaculate and cauda epididymal bull spermatozoa. Theriogenology, 43, 1301-1316. 